\title{
Why do children think they get discomfort related to daily
}

\section{activities?}

\author{
Jemma Coleman, Leon Straker and Marina Ciccarelli \\ Curtin University of Technology
}

Abstract

Children commonly report musculoskeletal discomfort related to different activities such as computer use, playing electronic games, watching TV, reading, and performing physical and hand intensive activities. Discomfort can result in disability and is a strong predictor of future discomfort in adulthood. Adult beliefs regarding discomfort can affect the level of disability and are modifiable. Children's beliefs regarding discomfort could potentially be modified to minimise disability related to musculoskeletal disorders. The aim of this study was to describe children's beliefs about why they experience musculoskeletal discomfort, both in general and related to specific activities. Eighty eight school children completed questionnaires on frequency and usual duration of nine activities, whether they had felt discomfort and what they believed was the cause of any discomfort in relation to those activities. The most common activity was TV watching, and most activities were performed for 1 hour or shorter. Bad posture and doing too much of a certain activity were the most common beliefs regarding reasons for discomfort. This study shows that children are developing beliefs that tend to reflect scientific 
knowledge about risk factors. These beliefs could be incorporated into preventative health interventions.

Keywords: young people, beliefs, musculoskeletal discomfort 


\section{Introduction}

It is common for children to report musculoskeletal discomfort related to different activities. Children using laptop [1], desktop [2, 3], and tablet computers [4] have indicated some level of discomfort related to computer use. Children have also reported discomfort related to playing electronic games [5, 6], watching TV [7] and reading [8]. Hand intensive activities, such as playing a musical instrument [9-11] and writing [8], have been associated with discomfort in children. Physical activities have been linked to back pain $[7,9,12,13]$ contusions, and strains [14].

Discomfort reported by children is not trivial as it can be sufficient to result in disability [7, 15]. It can result in school absence [16-19], visits to a health professional [7, 17-20], use of pain medication [19] and cause the cessation or modification of normal activities $[5,15,17,18,20,21]$. Discomfort can affect the quality of the child's life and have an impact on the life of the family [22]. At least one third of children will have a recurrent episode of lower back pain $[15,21]$, and discomfort in childhood has been shown to be a predictor of further discomfort in adulthood [19, 23-25]. Discomfort in childhood is therefore an important health issue.

In adulthood, beliefs towards discomfort are known to affect a person's level of disability [26]. Importantly, it has been shown that these beliefs can be modified, along with disability outcomes. Buchbinder et al. [27] used a population based intervention to improve beliefs about back pain in the 
general population. The intervention was not only effective in changing beliefs about back pain but also resulted in a decrease in the number of worker's compensation claims for back pain. Burton et al. [28] used an educational booklet to improve beliefs about back pain which led to a reduction in selfreported disability. Similarly, extended absence by industrial workers due to back pain was decreased in a study by Symonds et al. [29] using an educational pamphlet designed to alter avoidance beliefs.

Adults have a well developed understanding of health and illness as opposed to children, who exhibit developmental trends in their perspectives on discomfort [30]. Children may thus have either a positive or negative perceptions of pain and discomfort and may actually be less biased in terms of interpretation of pain and discomfort.

Children under 12 years of age have been reported to be generally confused about the cause and effect of discomfort and may believe that discomfort is caused by failure to comply with rules [30]. The beliefs of children over 12 years of age have been reported to be usually more developed, resembling a simplistic version of adult beliefs [31]. The majority of research into children's beliefs of discomfort has been on hospitalised children. The applicability of these findings to the development of preventative health interventions for the general healthy school aged population may therefore be limited.

There has been some research directly addressing children's beliefs of discomforts related to everyday activities. Jacobs et al. [3] asked children to 
report on musculoskeletal discomfort associated with different body parts and whether they perceived the discomfort was made worse with computer use. As an example, $58.3 \%$ of the cohort indicated that computer use did not change their neck discomfort intensity. However $35.4 \%$ of the children indicated that computer use made the discomfort worse. Wall et al. [32] reported on children's beliefs of the causes of back pain. Reasons suggested by the children included playing sports, lifting objects and being involved in a particular accident. When asked what activities they believed exacerbated their symptoms, the children's responses included physical activity and sitting and standing postures. The available studies have only considered specific activities and discomfort locations, so commonalities of beliefs across activities and body regions are not known.

Children appear to have only a partial understanding of the useful aspects of discomfort $[33,34]$. However, children with gymnastic training are able to explain how pain can be an indicator that something is wrong, or that they should stop their current activity [35]. These children could also describe the roles of the nerves and brain with pain and describe how discomfort tended to indicate that they were working physically hard and experiencing a training effect. This study suggests that, like in adults, some aspects of a child's beliefs about discomfort can be modified through intervention.

In summary, adult beliefs about some activity related discomforts are well developed and can be modified to reduce associated disability. However knowledge about children's beliefs concerning activity related discomfort is 
very limited. Better understanding of children's beliefs can assist in the design of more effective prevention initiatives for activity related musculoskeletal disorders and associated disability among children. This may reduce the discomfort related disability experience in childhood and also later in adulthood. The aim of this study therefore was to describe children's beliefs about why they experience musculoskeletal discomfort, both in general and related to specific activities.

\section{Method}

This study consisted of a questionnaire exploring the activities that children participate in, the discomfort they experience related to those activities, and their beliefs as to what caused any discomfort.

\subsection{Participants}

A convenience sample of 88 school children ( 44 male, 44 female) from grades 5 through 10 (age mean 13.0 years; range 11.0-16.9 years; standard deviation 1.5 years) enrolled in three private schools in Perth, Western Australia participated in this study. All schools provided students with access to computers, and one school had a laptop programme in place for students from grades 5-12. Students in grades 11 and 12 were not sampled from any school due to their preparation for pending examinations. Participants were recruited via school newsletters and questionnaires were administrated during the child's normal class time. Ninety-nine students from four classes originally 
consented to participate in the study, however a total 11 students were absent from the schools on the day the questionnaires were administered. Informed assent/consent was obtained from the child and their parent/guardian and ethics approval was granted by the Human Research Ethics Committee of Curtin University of Technology.

\subsection{Young people's Activity Questionnaire}

Children's activities and discomfort were assessed using the young people's activity questionnaire (YAQ). This questionnaire has previously been published and has been used in studies internationally. Whilst there has been no formal reliability and validity studies published on the YAQ, is was based on child pain perception and activity measures with evidence of reliability and validity and has been pilot tested by us on several occasions.

Students reported frequency and usual duration of nine activities; computer use at school and at home, use of electronic games, watching TV/DVD, reading, writing, playing a musical instrument, other hand intensive activities and vigorous physical activities. The frequency question was: "In the last month, how often did you ... (e.g. use a computer at school)?" with response options: didn't; 1 x month; 1x week; 2-3 x week; daily. The usual duration question was "In the last month, for how long did you usually...", with response options: $<30$ minutes; 30-60 minutes; $1-2$ hours; 2-5 hours; $>5$ hours. 
Participants were asked whether they had felt soreness at anytime in the last month using the question - "In the last month, how often did you feel any soreness, pain or discomfort?" with answer options: didn't; 1 x month; 1 x week; 2-3 x week; daily. If participants answered other than "didn't" they were asked to indicated the location of soreness on a body diagram, along with the intensity of soreness at each location on a numerical rating scale from 0 (no soreness) to 10 (extreme soreness). In a pilot study children from across the intended age range were given the questionnaire to complete then interviewed about their understanding of the questionnaire. The students indicated a better understanding of 'soreness' than 'discomfort' so that term was used for the remaining questions in the questionnaire. Participants were also asked the open ended question "What do you think caused this soreness?". Participants then reported the location of soreness felt in the last month and what they thought caused this soreness for each of the nine activities.

\subsection{Data analysis}

Data were screened for quality control and entered into SPSS v15. Frequency distributions were calculated for frequency and usual duration of use and for location of discomforts related to each activity. The children's answers to the open ended questions regarding causes of discomfort were analysed thematically. Each child's response was examined and considered in the context of all the children's responses. Various categories emerged from the data and each child's response was grouped with similar responses. Where a child gave more than one reason, reasons were analysed separately. 
Answers were left unclassified if they did not make sense, or if the child described the activity that they were participating in instead of which aspect of the activity was the cause of discomfort. The number of responses in each category was tallied and tabulated.

\section{Results}

\subsection{Activity frequency and usual duration}

Table 1 shows the last month's frequency and usual duration of the nine activities that were covered in the YAQ. The most common activity was TV watching, with 78 of the cohort watching daily. The next most frequent activities were writing, using a computer at school and reading. Nearly half of the group did not play electronic games, play a musical instrument, or perform any other hand intensive activities in the last month. The mode for all activities was 30-60 minutes, except for reading (mode <30mins).

INSERT TABLE 1 HERE

\subsection{Discomfort location related to activity}

Table 2 illustrates the reporting of discomfort per body part associated with each of the nine activities. Eye, mid and low back discomfort were most commonly related to using a computer at school, and neck discomfort was most commonly related to using a computer at home. Head discomfort was 
most commonly related to TV watching. Left shoulder/arm and elbow/hand discomfort in both arms, along with leg discomfort, were most commonly related to vigorous physical activities. Right elbow/hand soreness was most commonly related to writing. Playing a musical instrument was also a common reason for upper limb discomfort.

INSERT TABLE 2 HERE

\subsection{Discomfort beliefs}

The categories which emerged from the reasons children gave for their discomfort were; bad posture (e.g. "bending over work/computer"), technique (e.g. "doing wrong action for bowling cricket ball"), stillness (e.g. "sitting for too long in one position"), staring (e.g. "staring too long at one place"), too much (e.g. "too much writing"), working physically hard (e.g. "working hard"), inappropriate preparation (e.g. "not warming up"), particular incident (e.g. "with softball, ball hit knee"), previous known condition (e.g. "I have severs disease in my heels knees since I was 10") and unclassifiable (e.g. "daily activity").

Table 3 shows that the most frequently reported causes of discomfort were 'bad posture' ( $n=58)$ and 'doing too much' of the activity $(n=52)$. Children associated using a computer at school with discomfort stemming from 'bad posture' and 'doing too much', whilst using a computer at school was most commonly attributed to just 'bad posture'. There wasn't a clear reason for discomfort experienced when playing electronic games although 'too much', 'bad posture' and 'staring' were reported. Discomfort during TV watching and 
during reading was attributed to 'bad posture'. Children reported doing 'too much' as the main cause of discomfort when writing, however, 'bad posture' was also reported. Playing a musical instrument 'too much' and with 'bad posture' was believed to be the cause of discomfort related to this activity, which was similar to other hand intensive activities. 'Too much', 'inappropriate preparation', 'particular incidents' and 'working physically hard' were the most common reasons for discomfort related to vigorous physical activities, with the latter three only reported in relation to vigorous physical activities.

INSERT TABLE 3 HERE

\section{Discussion}

\subsection{Activity frequency and duration}

The majority of children in this study reported daily use of a computer at school and home, which concurs with a prior American study [5]. Daily TV use was reported by $70 \%$ of the group, which was similar to results of another American study that reported $81 \%$ of children had watched TV the previous day [36]. In this study, other common daily activities were reading and writing. Almost half of students indicated they did not play electronic games, play music or perform other hand intensive activities at all in the last month. An Australian report showed during non-school hours over a two week period, $49.5 \%$ of children participated in arts and crafts, while in the last year only 16.8\% played a musical instrument [37]. However, electronic game use within the Australian report was much higher (64\%) than that of the current study 
(56\%). The lesser amount of electronic game use seen in this study may be a result of the children's parental level of education influencing the child's time usage. All the children were from a private school, which suggests a higher socioeconomic status including education level. Better educated parents may be more aware of the potential problems associated with excessive electronic game playing and may also have the resources to offer their children other leisure activities such as team sports

\subsection{Location of discomfort related to activities}

The locations of discomfort related to particular activities reported in this study were consistent with prior child and adult study findings and were biomechanically/physiologically reasonable. For example, neck discomfort was mainly associated with using a computer at home, watching TV and reading [8]. It is likely that the furniture utilised at home during these activities was designed for adults and may have resulted in awkward postures of the head and neck, contributing to the child's discomfort [38]. Similarly, right elbow/hand discomfort was mainly associated with writing [9, 39], and leg discomfort was clearly related to vigorous physical activity, which is consistent with the lack of leg involvement associated with the other activities.

\subsection{Discomfort beliefs}

In this study, there were children who indicated that they were unsure of the reasons for their discomfort, regardless of the activity (See Table 3). Wall et al. [32] also had a large proportion of children indicate that they did not know what caused their back pain. This suggests that children's beliefs about the 
causes of activity related discomfort may be immature. It may therefore be possible to educate children about potential causes of discomfort.

The large number of 'unclassifiable' reasons for discomfort anytime and related to vigorous physical activity reflected the children's tendency to give an example of a sport or activity that they partook in, rather than explaining what aspect of the activity they thought caused the discomfort. It may be that the children did not understand the question and it would require an interview with the children to clarify this. However, they probably did understand the question as the high frequency of unclassifiable answers was not seen in the other activity categories. The inability to describe a cause again suggests an immature understanding, which may be amenable to education. However other reasons are possible, such as inadequate capturing of their beliefs in a questionnaire.

However children do hold causal beliefs and these should be considered when designing any intervention.

'Bad posture' was one of the most commonly cited reasons for discomfort, especially related to sedentary activities including using a computer, watching TV, reading and writing. Previous research suggests that posture is a possible risk factor for discomfort. Posture has been linked to neck pain [40-44] and back pain [41]. Computer use in adolescents has been shown to alter habitual sitting posture [45] and in the same cohort, computer use was linked to neck pain [46]. Interventions for children can build on this belief as discussions 
about correct posture will have meaning for children as they see this as linked to discomfort risk.

Doing 'too much' of a certain activity was another commonly given reason for discomfort. This indicates that children understand the concept of limiting the amount of time that they spend on an activity. However, doing 'too much' was only really perceived as important during writing and using a computer at school, activities not of the child's choosing. It may be that children do not associate doing too much of a 'fun' activity with being harmful, or do not notice the passing of time or the development of discomfort. It is not uncommon for athletes to experience "flow" during an activity, which can result in being totally absorbed in the activity, being unaware of their surrounds and feeling neither fatigue nor discomfort [47]. Flow has also been observed in children whilst participating in electronic games [48]. The perception of doing too much of a single activity leading to discomfort is an accurate one. Longer hours of computer use have been shown to be associated with discomfort in different body parts $[44,49,50]$. Likewise, overuse injuries due to physical activity are common and arise because of an increase in the duration of activity, amongst other factors [51]. Again, building on the belief of doing 'too much' can aid interventions for children, as it is obvious that many of them can already make the association between discomfort and doing 'too much'.

'Staring' could be considered a special case of 'doing too much'. Staring was mainly associated with computer use at school and home, and was given as a reason when the discomfort reported was located in the eyes or the head. The 
consistency of this finding adds validity to our results. Eye discomfort is commonly reported by adult computer users $[44,52]$ and has been reported in 5 year old children [53]. None of the children indicated that sitting too close to the TV or computer monitor caused their discomfort. It therefore appears that whilst children can identify 'doing too much' visual work is a risk, they may not be aware of other possible causes of eye discomfort.

A number of children reported not moving or 'stillness' to be the reason for their discomfort during using the computer at home, watching TV and particularly during reading (See table 3). This is an interesting finding as variation in posture is thought to be protective for musculoskeletal injuries [1, 54, 55]. Prevention interventions could therefore build on this developing understanding of the importance of movement.

A small percentage of the children identified poor technique as being related to discomfort during physical activity, music, and writing tasks, but the children did not relate the importance of technique to other activities including computer use. However, most children did not consider that the use of correct or 'safe' techniques was an important factor in being able to perform a task without discomfort. Therefore if children are taught how poor techniques can lead to discomfort this may help them better understand the importance of safe techniques in preventing discomfort.

The categories 'working physically hard', 'inappropriate preparation' and 'particular incident' were all related to vigorous physical activities, even when 
reported in the 'anytime' category. Vigorous physical activity resulted in the greatest diversity of answers, indicating that the children may have more knowledge in this area. Ninety one percent of children indicated that they performed vigorous physical activity at least once a week. Nemeth et al. [35] demonstrated that children trained in gymnastics could specify when discomfort was related to working hard or when it indicated that something was wrong and that they should stop. The children in the current study appeared to be more knowledgeable about possible causes of discomfort related to vigorous physical activities. This may reflect physical education curriculums which include information about sporting injuries, or it may reflect general public awareness of sports injuries from following popular spectator sports.

The aim of this study was to describe children's beliefs about why they experience musculoskeletal discomfort, both in general and related to specific activities. The evidence presented showed that children do have some beliefs about discomfort and that these often align to current scientific thinking. The evidence also showed that some children are unsure about the reasons for discomfort. Together this evidence enhances our understanding of children's beliefs concerning activity related discomfort. This better understanding can assist in the design of more effective prevention initiatives for activity related musculoskeletal disorders and associated disability among children to reduce the discomfort related disability experience in childhood and also later in adulthood. 


\subsection{Limitations}

This study has identified the beliefs of some children related to various activities, however a number of limitations should be considered when interpreting the findings. The study collected information from a small sample from one geographical area. How representative the beliefs reported here are for children in other areas is not known. Data were collected only by questionnaire and more detailed understanding of children's beliefs might have been developed using interviews. As the children participating in the study might not have been experiencing discomfort when they were filling in the questionnaire there may have been a recall bias if the children were unable to reliably remember associations between prior activity and discomfort.

\section{Conclusions}

This study has explored the beliefs of children about the causes of general and activity related discomfort. School aged children appear to be developing beliefs and these are often aligned with current scientific knowledge about risk factors. These developing beliefs should be used to inform and target preventative health interventions to reduce discomfort related disability.

\section{Acknowledgements}

The authors would like to thank the children, their parents and their schools for enabling this study and Greet Peirelinck for assistance in data collection and processing. 


\section{References}

[1] C. Harris and L. Straker, Survey of physical ergonomics issues associated with school children's use of laptop computers, International Journal of Industrial Ergonomics 26 (2000), 337-346.

[2] A. Burke and E. Peper, Cumulative trauma disorder risk for children using computer products: results of a pilot investigation with a student convenience sample, Public Health Reports 117 (2002), 350-357.

[3] K. Jacobs and N.A. Baker, The association between children's computer use and musculoskeletal discomfort, Work 18 (2002), 221-226.

[4] C.M. Sommerich, R. Ward, K. Sikdar, J. Payne and L. Herman, A survey of high school students with ubiquitous access to tablet PCs, Ergonomics 50 (2007), 706-727.

[5] E.M. Ramos, C.A. James and J. Bear-Lehman, Children's computer usage: Are they at risk of developing repetitive strain injury?, Work 25 (2005), 143-154.

[6] R. Gunzburg, F. Balague, M. Nordin, M. Szpalski, D. Duyck, D. Bull and C. Melot, Low back pain in a population of school children, European Spine Journal 8 (1999), 439-443.

[7] F. Balague, G. Dutoit and M. Waldburger, Low back pain in schoolchildren. An epidemiological study, Scandinavian Journal of Rehabilitation Medicine 20 (1988), 175-179.

[8] L. Straker, Are children at more risk of developing musculoskeletal disorders from working with computers or with paper?, in: International Society for Occupational Ergonomics and Safety XV Annual Conference, 
International Society for Occupational Ergonomics and Safety, Fairfax, Virginia, USA, 2001.

[9] H.J.H. Fry, Overuse syndrome of the upper limb in musicians, The Medical Journal of Australia 144 (1986), 182-185.

[10] S. Niemi, S. Levoska, J. Kemila, K. Rekola and S. KeinanenKiukaanniemi, Neck and shoulder symptoms and leisure time activities in high school students, Journal of Orthopaedic and Sports Physical Therapy 24 (1996), 25-29.

[11] D. Shoup, Survey of performance-related problems among high school and junior high school musicians, Medical Problems of Performing Artists 10 (1995), 100-105.

[12] K. Newcomer and M. Sinaki, Low back pain and its relationship to back strength and physical activity in children, Acta Paediatrica 85 (1996), 1433-1439.

[13] U.M. Kujala, J.J. Salminen, S. Taimela, A. Oksanen and L. Jaakkola, Subject characteristics and low back pain in young athletes and nonathletes, Medicine and Science in Sports and Exercise 24 (1992), 627-632.

[14] T.A. Adirim and T.L. Cheng, Overview of injuries in the young athlete, Sports Medicine 33 (2003), 75-81.

[15] J.J. Salminen, J. Pentti and P. Terho, Low back pain and disability in 14year-old schoolchildren, Acta Paediatrica 81 (1992), 1035-1039.

[16] M. Mikkelsson, J.J. Salminen and H. Kautiainen, Non-specific musculoskeletal pain in preadolescents. Prevalence and 1-year persistence, Pain 73 (1997), 29-35. 
[17] J.C. Fairbank, P.B. Pynsent, J.A. Van Poortvliet and H. Phillips, Influence of anthropometric factors and joint laxity in the incidence of adolescent back pain, Spine 9 (1984), 461-464.

[18] P. Viry, C. Creveuil and C. Marcelli, Nonspecific back pain in children. A search for associated factors in 14-year-old schoolchildren, Revue du Rhumatisme 66 (1999), 381-388.

[19] G. Brattberg, The incidence of back pain and headache among Swedish school children, Quality of Life Research 3 (1994), S27-31.

[20] T.L. Olsen, R.L. Anderson, S.R. Dearwater, A.M. Kriska, J.A. Cauley, D.J. Aaron and R.E. Laporte, The epidemiology of low back pain in an adolescent population, American Journal of Public Health 82 (1992), 606-608.

[21] S. Taimela, U.M. Kujala, J.J. Salminen and T. Viljanen, The prevalence of low back pain among children and adolescents: a nationwide, cohortbased questionnaire survey in Finland, Spine 22 (1997), 1132-1136.

[22] J.A.M. Hunfeld, C.W. Perquin, H.J. Duivenvoorden, A.A.J.M. HazebroekKampschreur, J. Passchier, L.W.A. Van Suijlekom-Smit and J.C. Van Der Wouden, Chronic pain and its impact on quality of life in adolescents and their families, Journal of Pediatric Psychology 26 (2001), 145-153.

[23] A. Hellsing and I. Bryngelsson, Predictors of musculoskeletal pain in men: a twenty-year follow-up from examination at enlistment, Spine 25 (2000), 3080-3086.

[24] M. Harreby, K. Neergaard, G. Hesselsoe and J. Kjer, Are radiologic changes in the thoracic and lumbar spine of adolescents risk factors for 
low back pain in adults? A 25-year prospective cohort study of 640 school children, Spine 20 (1995), 2298-2302.

[25] J.J. Salminen, M.O. Erkintalo, J. Pentti, A. Oksanen and M.J. Kormano, Recurrent low back pain and early disc degeneration in the young, Spine 24 (1999), 1316-1321.

[26] T.L. Symonds, A.K. Burton, K.M. Tillotson and C.J. Main, Do attitudes and beliefs influence work loss due to low back trouble?, Occupational Medicine 46 (1996), 25-32.

[27] R. Buchbinder, D. Jolley and M. Wyatt, Population based intervention to change back pain beliefs and disability: three part evaluation, British Medical Journal 322 (2001), 1516-1520.

[28] A.K. Burton, G. Waddell, K.M. Tillotson and N. Summerton, Information and advice to patients with back pain can have a positive effect: a randomized controlled trial of a novel education booklet in primary care, Spine 24 (1999), 2484-2491.

[29] T.L. Symonds, A.K. Burton, K.M. Tillotson and C.J. Main, Absence resulting from low back trouble can be reduced by psychosocial intervention at the work place, Spine 20 (1995), 2738-2745.

[30] A. Gaffney and E.A. Dunne, Children's understanding of the causality of pain, Pain 29 (1987), 91-104.

[31] C.S. Crow, Children's pain perspectives inventory (CPPI): developmental assessment, Pain 72 (1997), 33-40.

[32] E.J. Wall, S.L. Foad and J. Spears, Backpacks and back pain: Where's the epidemic?, Journal of Pediatric Orthopedics 23 (2003), 437-439. 
[33] M. Savedra, P. Gibbons, M. Tesler, J. Ward and C. Wegner, How do children describe pain? A tentative assessment, Pain 14 (1982), 95-104.

[34] P.J. Mcgrath, Annotation: Aspects of pain in children and adolescents, Journal of Child Psychology and Psychiatry 36 (1995), 717-730.

[35] R.L. Nemeth, C.L. Von Baeyer and E.M. Rocha, Young gymnasts' understanding of sport-related pain: a contribution to prevention of injury, Child: Care, Health and Development 31 (2005), 615-625.

[36] D.L. Roberts, U.G. Foehr and V. Rideout (2005) Generation M: Media in the lives of 8-18 year olds. Menlo Park, CA, The Henry J. Kaiser Family Foundation.

[37] Australian Bureau of Statistics (2006) Children's participation in cultural and leisure activities, Australia. Canberra: ACT, Australian Bureau of Statistics.

[38] L. Straker, R. Burgess-Limerick, C. Pollock, J. Coleman, R. Skoss and B. Maslen, Children's posture and muscle activity at different computer display heights and during and paper information technology use, Human Factors 50 (2008), 49-61.

[39] P.C. Jedynak, C. Tranchant and D. Zegers De Beyl, Prospective clinical study of writer's cramp, Movement Disorders 16 (2001), 494-499.

[40] G.A.M. Ariens, P.M. Bongers, M. Douwes, M.C. Miedema, W.E. Hoogendoorn, G. Van Der Wal, L.M. Bouter and W. Van Mechelen, Are neck flexion, neck rotation, and sitting at work risk factors for neck pain? Results of a prospective cohort study, Occupational and Environmental Medicine 58 (2001), 200-207. 
[41] S. Murphy, P. Buckle and D. Stubbs, Classroom posture and selfreported back and neck pain in schoolchildren, Applied Ergonomics 35 (2004), 113-120.

[42] D.D. Harrison, D.E. Harrison, T.J. Janik, R. Cailliet, J.R. Ferrantelli, J.W. Haas and B. Holland, Modeling of the sagittal cervical spine as a method to discriminate hypolordosis: results of elliptical and circular modeling in 72 asymptomatic subjects, 52 acute neck pain subjects, and 70 chronic neck pain subjects, Spine 29 (2004), 2485-2492.

[43] K. Harms-Ringdahl and J. Ekholm, Intensity and character of pain and muscular activity levels elicited by maintained extreme flexion position of the lower-cervical-upper-thoracic spine, Scandinavian Journal of Rehabilitation Medicine 18 (1986), 117-126.

[44] J. Faucett and D.M. Rempel, VDT-related musculoskeletal symptoms: Interactions between work posture and psychosocial work factors, American Journal of Industrial Medicine 26 (1994), 597-612.

[45] L. Straker, P.B. O'Sullivan, A. Smith and M.C. Perry, Computer use and habitual spinal posture in Australian adolescents, Public Health Reports 122 (2007), 634-643.

[46] L. Straker, P. O' Sullivan, G. Kendall, N. Sloan, C.M. Pollock, A. Smith and M.C. Perry, IT kids: exposure to computers and adolescents' neck posture and pain, in: International Ergonomics Association Triennial Congress 2006, R. N. Pikaar, E. A. P. Koningsveld and P. J. M. Settels Eds, Elsevier, Maastricht; Netherlands, 2006.

[47] M.A. Browne and M.J. Mahoney, Sport Psychology, Annual Review of Psychology 35 (1984), 605-625. 
[48] Y. Inal and K. Cagiltay, Flow experiences of children in an interactive social game environment British Journal of Educational Technology 38 (2007), 455-464.

[49] C. Jensen, L. Finsen, K. Sogaard and H. Christensen, Musculoskeletal symptoms and duration of computer and mouse use, International Journal of Industrial Ergonomics 30 (2002), 265-275.

[50] B.M. Blatter and P.M. Bongers, Duration of computer use and mouse use in relation to musculoskeletal disorders of neck or upper limb, International Journal of Industrial Ergonomics 30 (2002), 295-306.

[51] F.G. O'connor, T.M. Howard, C.M. Fieseler and R.P. Nirschl, Managing overuse injuries: A systematic approach, The Physician and Sportsmedicine 25 (1997), 00-00.

[52] R. Iribarren, A. Fornaciari and G.K. Hung, Effect of cumulative nearwork on accommodative facility and asthenopia, International Ophthalmology 24 (2001), 205-212.

[53] L.M. Straker, C.M. Pollock, S.R. Zubrick and J.J. Kurinczuk, The association between information and communication technology exposure and physical activity, musculoskeletal and visual symptoms and socio-economic status in 5-year-olds, Child: Care, Health and Development 32 (2006), 343-351.

[54] A. Delisle, C. Lariviere, A. Plamondon and D. Imbeau, Comparison of three computer office workstations offering forearm support: impact on upper limb posture and muscle activation, Ergonomics 49 (2006), 139160. 
[55] S.E. Mathiassen, Diversity and variation in biomechanical exposure: What is it, and why would we like to know?, Applied Ergonomics 37 (2006), 419-427. 


\section{Table Captions}

Table 1. Frequency and usual duration of children's activities (n)

Table 2. Number of complaints per body part attributed to a particular activity

(n)

Table 3. Children's reasons for discomfort by category and activity (n) 
Table 1. Frequency and usual duration of children's activities (n)

\begin{tabular}{|c|c|c|c|c|c|c|c|c|c|}
\hline & $\begin{array}{c}\text { Using a } \\
\text { computer at } \\
\text { school }\end{array}$ & $\begin{array}{c}\text { Using a } \\
\text { computer at } \\
\text { home }\end{array}$ & $\begin{array}{c}\text { Electronic } \\
\text { games }\end{array}$ & TV & Reading & Writing & Music & $\begin{array}{c}\text { Other } \\
\text { hand } \\
\text { intensive } \\
\text { activities }\end{array}$ & $\begin{array}{l}\text { Vigorous } \\
\text { physical } \\
\text { activities }\end{array}$ \\
\hline \multicolumn{10}{|l|}{ Frequency } \\
\hline Didn't & 1 & 5 & 39 & 0 & 2 & 8 & 40 & 35 & 6 \\
\hline $1 \times$ month & 4 & 3 & 12 & 2 & 3 & 3 & 2 & 12 & 2 \\
\hline $1 \times$ week & 14 & 8 & 17 & 7 & 1 & 8 & 7 & 14 & 21 \\
\hline 2-3 x week & 15 & 36 & 11 & 8 & 21 & 10 & 17 & 16 & 31 \\
\hline Daily & 54 & 32 & 9 & 70 & 51 & 59 & 21 & 11 & 27 \\
\hline \multicolumn{10}{|l|}{ Usual duration } \\
\hline$<30$ minutes & 19 & 12 & 19 & 8 & 35 & 31 & 19 & 14 & 9 \\
\hline $30-60$ minutes & 31 & 36 & 17 & 33 & 34 & 33 & 23 & 19 & 39 \\
\hline 1-2 hours & 8 & 22 & 9 & 26 & 11 & 9 & 3 & 17 & 25 \\
\hline $2-5$ hours & 14 & 7 & 2 & 16 & 5 & 4 & 1 & 2 & 8 \\
\hline$>5$ hours & 14 & 2 & 2 & 2 & 1 & 2 & 1 & 0 & 1 \\
\hline
\end{tabular}


Table 2. Number of complaints per body part attributed to a particular activity (n). * Stomach pain was only measured at anytime not during the particular activities.

\begin{tabular}{|c|c|c|c|c|c|c|c|c|c|c|}
\hline & Anytime & $\begin{array}{c}\text { Using a } \\
\text { computer } \\
\text { at school }\end{array}$ & $\begin{array}{c}\text { Using a } \\
\text { computer at } \\
\text { home }\end{array}$ & $\begin{array}{c}\text { Electronic } \\
\text { games }\end{array}$ & TV & Reading & Writing & Music & $\begin{array}{l}\text { Other hand } \\
\text { intensive } \\
\text { activities }\end{array}$ & $\begin{array}{l}\text { Vigorous } \\
\text { physical } \\
\text { activities }\end{array}$ \\
\hline Eyes & 10 & 9 & 4 & 3 & 5 & 5 & 2 & 1 & 0 & 1 \\
\hline Head & 31 & 6 & 4 & 5 & 8 & 5 & 6 & 5 & 1 & 5 \\
\hline Neck & 26 & 8 & 13 & 6 & 12 & 13 & 8 & 4 & 5 & 5 \\
\hline Mid back & 13 & 9 & 4 & 3 & 4 & 2 & 4 & 5 & 1 & 6 \\
\hline Low back & 16 & 8 & 4 & 1 & 5 & 4 & 6 & 2 & 4 & 7 \\
\hline Left shoulder/arm & 7 & 1 & 0 & 1 & 1 & 2 & 2 & 5 & 4 & 9 \\
\hline Left elbow/hand & 7 & 5 & 2 & 2 & 1 & 1 & 4 & 6 & 5 & 8 \\
\hline Right shoulder/arm & 14 & 2 & 0 & 1 & 2 & 1 & 4 & 7 & 5 & 9 \\
\hline Right elbow/hand & 7 & 7 & 2 & 3 & 1 & 1 & 14 & 8 & 8 & 10 \\
\hline Legs & 33 & 4 & 2 & 0 & 5 & 0 & 2 & 2 & 5 & 26 \\
\hline Stomach* & 11 & & & & & & & & & \\
\hline
\end{tabular}


Table 3. Children's reasons for discomfort by category and activity (n)

\begin{tabular}{|c|c|c|c|c|c|c|c|c|c|c|c|}
\hline & Anytime & $\begin{array}{l}\text { Computer } \\
\text { at school }\end{array}$ & $\begin{array}{l}\text { Computer } \\
\text { at home }\end{array}$ & $\begin{array}{l}\text { Electronic } \\
\text { games }\end{array}$ & TV & Reading & Writing & Music & $\begin{array}{c}\text { Other } \\
\text { hand } \\
\text { intensive } \\
\text { activities }\end{array}$ & $\begin{array}{l}\text { Vigorous } \\
\text { physical } \\
\text { activities }\end{array}$ & Total \\
\hline Bad posture & 6 & 7 & 8 & 2 & 10 & 9 & 8 & 3 & 4 & 1 & 58 \\
\hline Technique & 0 & 0 & 0 & 0 & 0 & 0 & 1 & 1 & 0 & 1 & 3 \\
\hline Stillness & 0 & 0 & 1 & 0 & 1 & 3 & 0 & 0 & 0 & 0 & 5 \\
\hline Staring & 3 & 5 & 4 & 2 & 1 & 1 & 1 & 0 & 0 & 0 & 17 \\
\hline Too much & 7 & 8 & 4 & 3 & 3 & 2 & 12 & 5 & 3 & 5 & 52 \\
\hline Working physically hard & 0 & 0 & 0 & 0 & 0 & 0 & 0 & 0 & 0 & 3 & 3 \\
\hline $\begin{array}{l}\text { Inappropriate } \\
\text { preparation }\end{array}$ & 1 & 0 & 0 & 0 & 0 & 0 & 0 & 0 & 0 & 4 & 5 \\
\hline Particular incident & 8 & 0 & 0 & 0 & 0 & 0 & 0 & 0 & 0 & 4 & 12 \\
\hline $\begin{array}{l}\text { Previous known } \\
\text { condition }\end{array}$ & 2 & 0 & 0 & 0 & 0 & 0 & 1 & 0 & 1 & 2 & 6 \\
\hline Unclassifiable & 27 & 1 & 3 & 0 & 1 & 0 & 1 & 1 & 4 & 10 & 48 \\
\hline Not sure & 8 & 4 & 4 & 1 & 3 & 5 & 3 & 1 & 4 & 5 & 38 \\
\hline
\end{tabular}

